\title{
Obesity and female fertility: a primary care perspective
}

\author{
Scott Wilkes, Alison Murdoch
}

\begin{abstract}
Infertility affects approximately one in six couples during their lifetime. Obesity affects approximately half of the general population and is thus a common problem among the fertile population. Obese women have a higher prevalence of infertility compared with their lean counterparts. The majority of women with an ovulatory disorder contributing to their infertility have polycystic ovary syndrome (PCOS) and a significant proportion of women with PCOS are obese. Ovulation disorders and obesity-associated infertility represent a group of infertile couples that are relatively simple to treat. Maternal morbidity, mortality and fetal anomalies are increased with obesity and the success of assisted reproductive technology (ART) treatments is significantly reduced for
\end{abstract}

\section{Introduction}

Obesity is an increasing problem encountered by general practitioners (GPs) and its impact on fertility is significant. Approximately half of the USA, UK, European and Australian population are overweight or obese. ${ }^{1}$ In the UK, the GP contract, through the Quality and Outcomes Framework (QOF) points system, encourages GPs to identify obese patients in their practice population. However, to date there is no contractual obligation upon GPs to manage their obese population. National Institute for Health and Clinical Excellence (NICE) guidelines for the management of obesity focus upon environmental strategies and drug therapies. ${ }^{2}$ Despite these guidelines there is only modest evidence to suggest nurse-led intervention and follow-up can achieve a sustained weight loss of $3 \mathrm{~kg}$ at 1 year. ${ }^{3}$ General practice may have a significant contribution to make to the management of obesity and the infertile obese population. This paper reviews the impact of obesity upon female fertility from a primary care perspective, reviewing policy and practice guidelines, effect of obesity upon conception rates, health risks, economic costs and management strategies for the obese infertile population.

\section{Literature search}

MEDLINE and PubMed searches were carried out for the period July 1998 to June 2008 with the following search terms: 'infertility, female' and 'obesity'. A total of 61 citations were found. In addition, the reference lists of the papers were reviewed and relevant articles sought. A search of the Cochrane Database revealed no directly relevant systematic reviews. NICE guidance on Obesity: The Prevention, Identification, Assessment and Management of

Centre for Primary and Community Care, School of Health Natural and Social Sciences, University of Sunderland, Sunderland, UK

Scott Wilkes, PhD, MRcGP, General Practitioner/Senior Academic General Practitioner

Newcastle Fertility Centre at LIFE, BioScience Centre, International Centre for Life, Newcastle upon Tyne, UK Alison Murdoch, MD, FRCOG, Professor

Correspondence to: Dr Scott Wilkes, Institute of Health and Society, Newcastle University, 21 Claremont Place, Newcastle upon Tyne NE2 4AA, UK. E-mail: scott.wilkes@newcastle.ac.uk obese women. Body mass index (BMI) treatment limits for ART throughout the UK vary. The mainstay for treatment is weight loss, which improves both natural fertility and conception rates with ART. The most cost-effective treatment strategy for obese infertile women is weight reduction with a hypo-caloric diet. Assisted reproduction is preferable in women with a BMl of $30 \mathrm{~kg} / \mathrm{m}^{2}$ or less and weight loss strategies should be employed within primary care to achieve that goal prior to referral.

Keywords family practice, infertility, obesity, polycystic ovary syndrome, primary care

J Fam Plann Reprod Health Care 2009; 35(3): 181-185

(Accepted 22 April 2009)

\section{Key message points}

- Primary care has a significant role to play in the management of obese infertile women but is not compelled to manage its obese population.

- Obese women have a higher prevalence of infertility, maternal morbidity, mortality and fetal anomalies.

- Weight loss improves natural fertility and conception rates with assisted reproductive technology (ART), and reduces maternal and fetal morbidity and mortality.

- Weight loss is the most cost-effective treatment strategy for anovulation in obese infertile women.

- The success of ART in obese women is significantly reduced when compared with non-obese women.

Overweight and Obesity in Adults and Children ${ }^{2}$ and Fertility: Assessment and Treatment for People with Fertility Problems ${ }^{4}$ were reviewed.

\section{Obesity and fertility in context}

Obesity represents a significant cause of infertility, 5 its negative effect having been recognised since the days of Hippocrates:

"The girls get amazingly flabby and podgy ... People of such constitution cannot be prolific ... fatness and flabbiness are to blame. The womb is unable to receive the semen and they menstruate infrequently and little. As good proof of the sort of physical characteristics that are favourable to conception, consider the case of serving wenches. No sooner do they have intercourse with a man than they become pregnant, on account of their sturdy physique and their leanness of flesh." 6

More recently, oligo-ovulation, obesity and hyperandrogenism were recognised with the eponymous syndrome of Stein and Leventhal characterised by oligomenorrhoea, obesity and hirsutism. ${ }^{7}$ However, the current obesity epidemic is largely diet/lifestyle-related.

A simple method of assessing obesity is body mass index (BMI) (Table 1) although BMI is not universally appropriate and does not take account of central adiposity or ethnic variation. Waist circumference would be more accurate in, for example, Asians and body builders. Estimates of obesity and overweight throughout European countries vary between $30 \%$ and $80 \% .8$ Approximately $15 \%$ of women undergoing ART are overweight or obese. ${ }^{9}$ 
Table 1 Obesity classification according to the World Health Organization

\begin{tabular}{ll}
\hline Body mass index (BMI) $\mathbf{( k g / \mathbf { m } ^ { 2 } )}$ & Weight classification \\
\hline$<18.5$ & Underweight \\
$18.5-24.9$ & Healthy weight \\
$\geq 25-29.9$ & Overweight \\
$\geq 30$ & Obese \\
\hline
\end{tabular}

Obesity has an impact on many aspects of reproductive health. In relation to fertility, it is most commonly associated with polycystic ovary syndrome (PCOS).

\section{Simple obesity and PCOS}

Fertility is adversely affected by simple obesity, PCOS and particularly in obese women with PCOS.${ }^{10}$ One quarter of all infertile couples have an ovulatory disorder ${ }^{11}$ and $90 \%$ of those women with an ovulatory disorder have PCOS. 12 Most women with PCOS are overweight, with estimates of the prevalence of obesity in PCOS ranging from $35 \%$ to 63\%.12-15 Whilst not all women with PCOS are obese, PCOS is associated with a disorder of energy balance, which predisposes to obesity. ${ }^{10}$ Notwithstanding this predisposition, which is often used by patients as an excuse for weight reduction failure, obesity in those with PCOS is often the result of diet and not the endocrine disorder. Of all women of reproductive age, up to $10 \%$ have PCOS. 16

Simple obesity and PCOS are associated with the development of hyperinsulinaemia and hyperandrogenism. ${ }^{17}$ The related chronic anovulation leads to decreased fertility. ${ }^{10}$

Simple obesity is associated with many medical conditions including type 2 diabetes mellitus, cardiovascular disease, osteoarthritis, sleep apnoea, breast cancer, uterine cancer, PCOS and the metabolic syndrome. Abdominal adiposity and insulin resistance are features of simple obesity. Insulin resistance and hyperinsulinaemia play a pivotal role in the infertility of obese patients. Insulin stimulates steroidogenesis in the ovary resulting in raised serum androgens and also decreases liver synthesis of sex hormone binding globulin (SHBG), the carrier protein for sex steroid hormones. Adipose tissue stores excess sex steroids, which are readily available and raise plasma androgens. The above mechanisms have a deleterious effect upon the ovulatory capacity of the ovary. ${ }^{10}$

PCOS is the most common endocrine disorder affecting women characterised by oligo- and/or anovulation, clinical and/or biochemical signs of hyperandrogenism and polycystic ovaries. ${ }^{18,19}$ It is the excess androgen production that is thought to contribute to abnormal secretion of luteinising hormone, abdominal adiposity and insulin resistance. ${ }^{10}$ PCOS is believed to have a genetic predisposition that is exacerbated by obesity. ${ }^{17}$ Androgen excess in utero may also be responsible for programming and the subsequent development of PCOS. ${ }^{20}$ Whilst weight reduction of obese women with PCOS falls within the remit of the generalist, the management of PCOS per se is challenging, should be symptom orientated and performed by those with expertise. ${ }^{21}$

\section{Policy and practice guidelines}

The British Fertility Society (BFS) recommends that women should aim for a normal BMI before starting any form of fertility treatment. ${ }^{22}$ Specifically, it advises deferring treatment until the BMI is less than $35 \mathrm{~kg} / \mathrm{m}^{2}$ and treatment is preferable with a BMI of $30 \mathrm{~kg} / \mathrm{m}^{2}$ or less. Assisted reproductive technology (ART) treatments offered to obese women in fertility clinics throughout the UK vary. For example, differing BMI limits are applied between fertility units for in vitro fertilisation (IVF) treatment but also differing BMI limits are applied within units related to access to IVF and clomifene treatment. ${ }^{23}$ Fifty per cent of licensed ART units apply BMI limits to clomifene treatment and $70 \%$ to ART treatments. ${ }^{23}$ Those limits vary between 25 and $40 \mathrm{~kg} / \mathrm{m}^{2}$. There is also variation in the approach of fertility units in the treatment of obesity, with $20 \%$ of units using orlistat as part of a weight reduction programme and $50 \%$ using metformin to overcome insulin resistance encountered in simple obesity and obese women with PCOS.23 The ethical issues in imposing BMI treatment limits for obese women are those of informed patient choice, health risks, success rates and private practice of licensed fertility units. By imposing BMI treatment limits we are removing patient autonomy and informed decision making by the infertile couple. Should obese women have the right to choose a course of action, assuming that course of action is fully informed, that puts themselves and their unborn child at risk? After all, normally fertile obese women do have the right to, and do become pregnant. Whilst it has been acknowledged that BMI treatment limits provide a tool for National Health Service (NHS) rationing of fertility treatments, the arguments for imposing BMI limits are patient safety, improved conception rates, both naturally and with ART.

\section{Effect of obesity on conception rates}

The conception rates for the normal fertile population is approximately $30 \%$ per cycle 24 with a cumulative success rate of $84 \%$ at 1 year. ${ }^{4}$ Similar success rates of $30 \%$ per cycle are also typical with ART. ${ }^{25}$

Women with simple obesity have reduced fertility and experience lower success rates per cycle. ${ }^{26}$ The success of ART in obese women is significantly reduced when compared with non-obese women.9,27-30 These lower success rates with ART are associated with central adiposity 29 and ART becomes less successful with increasing obesity. ${ }^{31}$

Women with PCOS who are obese menstruate less frequently and are less likely to respond to ovulation induction when compared with their lean counterparts. ${ }^{13,32}$ However, weight reduction in obese women with PCOS profoundly increases their chance of conception both spontaneously and with ovulation induction. $33-35$

\section{Health risks for obese infertile women}

Maternal mortality is increased in obesity. In the 2002 Confidential Enquiry into Maternal and Child Health, 35\% of the women who died were obese. ${ }^{36}$ Obesity is responsible for $80 \%$ of anaesthetic-related deaths and $18 \%$ of obstetric deaths. ${ }^{37}$ Obesity carries a greater risk of gestational diabetes, thromboembolism, hypertension and Caesarean section. ${ }^{12,38-41}$ Obese women with PCOS require higher doses of gonadotrophins to stimulate ovulation in ART cycles compared with their lean counterparts, $32,42,43$ are more difficult to monitor with ultrasound, and carry an increased risk of ovarian hyperstimulation syndrome and multiple pregnancies. ${ }^{12}$ There is a greater risk of miscarriage in obese women, 38,39 which is reversed with weight loss. ${ }^{34}$ Other risks include congenital anomalies, including neural tube defects and cardiac malformations, and intrapartum problems. ${ }^{12}$ Maternal obesity is increasing and accelerating and has been shown to be associated with socioeconomic deprivation. 44 


\section{Economic costs of obese infertile women}

In an economic evaluation in Australian women, 67 anovulatory women received fertility treatment at a cost of $\$ 550000$ to achieve two live births. The same women then underwent a lifestyle programme including a hypo-caloric diet and exercise resulting in 45 babies and a cost of $\$ 210000.45$ In simple terms, the weight loss programme resulted in a cost per child reduction from $\$ 275000$ to $\$ 4700$. However a recent cross-sectional survey of 1756 women in a tertiary care fertility unit demonstrated no difference in the cost per live birth resulting from IVF when comparing underweight, overweight and obese class I to women with normal BMI. ${ }^{46}$ The authors did recommend weight reduction to reduce obstetric complications. Additionally obese mothers cost five times more to look after compared with their lean counterparts. ${ }^{47}$ Nurse-led primary care weight management in the UK has been shown to be effective ${ }^{3}$ and $8 \%$ of the programme costs are recouped by the subsequent non-prescription of drugs. ${ }^{48}$ Assuming resumption of ovulation ${ }^{34}$ a significant proportion will not proceed to ART following spontaneous conception thus giving further cost savings.

\section{Management of anovulation in obese infertile women}

Weight loss is key to the management of obesity-related anovulation. The BFS recommend assistance with weight loss using psychological support, dietary advice, exercise classes and, where appropriate, drug therapy or bariatric surgery. ${ }^{22}$ The first-line treatment of obese infertile women with or without PCOS is lifestyle intervention including a hypo-caloric diet. ${ }^{17}$ Weight loss results in a reversal of the obesity-associated adverse biochemical profile with decreased insulin resistance and a resumption of menstrual regularity and ovulatory function. ${ }^{17}$ Moderate weight loss and a reduction in abdominal obesity improves menstrual regularity, ovulation and subsequent fertility in obese women. ${ }^{16}$ As little as a $5-10 \%$ reduction in BMI in obese infertile women results in improvement in outcome for all forms of fertility treatment. ${ }^{45}$ Clark et al. ${ }^{34}$ demonstrated that a weight loss of $14 \mathrm{lbs}$ (approximately 6\% of initial body weight) is associated with resumption of ovulation in some anovulatory women and an increase in pregnancy rate. A similar observation occurs with weight loss in obese women with $\operatorname{PCOS}^{34,45,49}$ as well as an improvement in biochemical markers with increased SHBG and reduced serum testosterone. $33,49,50$

Dietary treatment of obesity aims to increase calorie expenditure over calorie intake. This is best achieved by combining exercise with a reduction in calorie intake of approximately 500 calories per day with only $30 \%$ of daily calories coming from fat. ${ }^{16}$ Peer group support has been shown to be successful in reducing weight and improving pregnancy rates for obese infertile women. ${ }^{51}$ Patients are reluctant to present to their GP with concerns about their weight; they perceive there is little or no NHS support for weight management and feel stigmatised. 52 They are, however, aware of their own responsibilities for weight management and feel primary care is the best place to deliver the service, ${ }^{52}$ but primary care staff are disillusioned with the lack of success in the general obese population and lack of successful interventions available. ${ }^{53}$ Nevertheless, obese infertile women represent a cohort of patients more motivated and receptive to weight reduction strategies employed within general practice.

Drug therapy should be considered as adjunctive therapy with lifestyle modification and hypo-caloric dieting. 12,17,54 Pharmacotherapies aimed primarily at weight reduction include orlistat, sibutramine and rimonobant. Sibutramine and rimonobant are not recommended for women trying to conceive. Insulinsensitising agents such as metformin, commonly used in the treatment of type 2 diabetes mellitus, may decrease plasma insulin and associated hyperandrogenism but its role in anovulatory PCOS remains unclear. ${ }^{22,55}$ The glitazone family of drugs also decrease insulin and circulating androgens, but there is no trial evidence to show their effect in humans on obesity-related infertility. ${ }^{17}$ Clomifene is an effective ovulation induction agent but its effect is severely reduced in the obese patient ${ }^{56}$ and its use in obesity-related anovulation should be reserved for use by fertility specialists.

There are limited data suggesting improved reproductive function following bariatric surgery, ${ }^{57}$ however surgical intervention may be warranted to prevent potential adverse outcomes of pregnancy in obese women. ${ }^{58}$ Bariatric surgery remains a third-line treatment option. The biggest challenge, however, is to prevent the $90 \%$ of people who successfully lose weight from relapsing. 59

\section{Conclusions}

The prevalence of obesity is increasing and with it ovulatory dysfunction and female infertility. Establishing a diagnosis of anovulation in obese women in general practice is relatively straightforward. The most costeffective treatment for anovulation in obese infertile women is weight loss. Weight loss should be promoted as the best treatment for the obese infertile woman with menstrual irregularity and ovulatory infertility. ${ }^{16}$ Support for these patients in general practice should aim to reduce weight until resumption of ovulation; this may be as little as a $5-10 \%$ reduction in BMI for some women. NICE and the BFS recommend reducing BMI to below $30 \mathrm{~kg} / \mathrm{m}^{2}$ before inducing ovulation with clomifene or gonadotrophins. ${ }^{4}$ It is the authors' experience that obese infertile women are commonly referred back to primary care for weight management. For the NHS, primary care may be the best place to adopt weight management strategies for the infertile couple ${ }^{16}$ with clinical guidelines to support this role $^{2}$ and modest evidence demonstrating clinically significant weight loss. ${ }^{3}$ Currently the GP QOF system ensures that practices can produce a register of patients aged 16 years and over with a BMI $\geq 30 \mathrm{~kg} / \mathrm{m}^{2}$ in the last 15 months. The management of this cohort is variable. Some practices offer dietary advice and support; others advocate private support (e.g. WeightWatchers ${ }^{\circledR}$ ) while some Primary Care Trusts and local Councils invest in exercise programmes in local gymnasiums, for example. A more recent useful resource that general practice can direct obese patients to is the NHS 'Change for Life' website. ${ }^{60}$ All of these strategies aim to reduce calorie intake and increase calorie expenditure.

Obese women should be encouraged to lose weight for three reasons: first, there is a significant chance of recovery of natural fertility; second, ART procedures are more likely to succeed; and third, maternal morbidity and mortality will be reduced. Doctors may insist on weight reduction, which is a proven therapeutic option to improve fertility and also reduce the associated risks to both mother and unborn child. In line with the BFS recommendation the authors suggest that assisted reproduction is preferable in women with a BMI of $30 \mathrm{~kg} / \mathrm{m}^{2}$ or less and weight loss strategies should be employed within primary care to achieve that goal prior to referral. 
Statements on funding and competing interests

Funding The authors would like to acknowledge the NHS National Coordinating Centre for Research Capacity Development who funded this work through a National Institute for Health Research (NIHR) award held by Dr Scott Wilkes; Primary Care Researcher Development Award, National Coordinating Centre for Research Capacity Development, Leeds Innovation Centre, 103 Clarendon Road, Leeds LS2 9DF, UK. All the researchers involved in the production of this paper are independent from the funder.

Competing interests None identified.

\section{References}

International Obesity Taskforce and International European Association for the Study of Obesity website. 2002. www.iotf.org/database/index.asp [Accessed 14 July 2008].

2 National Institute for Health and Clinical Excellence (NICE). Obesity: The Prevention, Identification, Assessment and Management of Overweight and Obesity in Adults and Children (Clinical Guideline No. 43). 2006. http://www.nice.org.uk/ guidance/CG43 [Accessed 14 July 2008].

3 Counterweight Project Team. Evaluation of the Counterweight Programme for obesity management in primary care: a starting point for continuous improvement. $\mathrm{Br} J$ Gen Pract 2008; 58: 548-554.

4 National Institute for Health and Clinical Excellence (NICE). Fertility: Assessment and Treatment for People with Fertility Problems (Clinical Guideline No. 11). http://www.nice.org.uk/ CG011 [Accessed 14 July 2008].

5 Norman RJ, Clark AM. Obesity and reproductive disorders: a review. Reprod Fertil Dev 1998; 10: 55-63.

6 Chadwick J, Mann WN. Medicine: Airs, Waters, Places (an essay on the influence of climate, water supply and situation on health). Hippocratic Writings. London, UK: Penguin Classics, 1983; 164-165

7 Stein IF, Leventhal ML. Amenorrhoea associated with bilateral polycystic ovaries. Am J Obstet Gynecol 1934; 29: 181-191.

8 World Health Organization (WHO). 10 Things You Need to Know About Obesity. http://www.euro.who.int/Document/NUT/ ObesityConf_10things_Eng.pdf [Accessed 14 November 2007].

9 Lintsen AME, Pasker-de Jong PCM, de Boer EJ, Burger CW, Jansen CAM, Braat DDM, et al. Effects of subfertility cause, smoking and body weight on the success rate of IVF. Hum Reprod 2005; 20: 1867-1875.

10 Franks S. Genetic and environmental origins of obesity relevant to reproduction. Reprod Biomed Online 2006; 12: 526-531.

11 Templeton A, Fraser C, Thompson B. The epidemiology of infertility in Aberdeen. BMJ 1990; 301: 148-152.

12 Balen AH, Dresner M, Scott EM, Drife JO. Should obese women with polycystic ovary syndrome receive treatment for infertility? BMJ 2006; 332: 434-435.

13 Kiddy DS, Sharp PS, White DM, Scanlon MF, Mason HD, Bray $\mathrm{CS}$, et al. Differences in clinical and endocrine features between obese and non-obese subjects with polycystic ovary syndrome: an analysis of 263 consecutive cases. Clin Endocrinol 1990; 32: 213-220.

14 Norman RJ, Masters SC, Hague W, Beng C, Pannall P, Wang $\mathrm{JX}$, et al. Metabolic approaches to the subclassification of polycystic ovary syndrome. Fertil Steril 1995; 63: 329-335.

15 Franks S. Polycystic ovary syndrome: a changing perspective. Clin Endocrinol 1989; 31: 87-120.

16 Moran LJ, Norman RJ. The obese patient with infertility: a practical approach to diagnosis and treatment. Nutr Clin Care 2002; 5: 290-297.

17 Pasquali R, Pelusi C, Genghini S, Cacciari M, Gambineri A. Obesity and reproductive disorders in women. Hum Reprod Update 2003; 9: 359-372.

18 The Rotterdam ESHRE/ASRM-sponsored PCOS Consensus Workshop Group. Revised 2003 consensus on diagnostic criteria and long-term health risks related to polycystic ovary syndrome (PCOS). Hum Reprod 2004; 19: 41-47.

19 Bhathena RK. Therapeutic options in the polycystic ovary syndrome. J Obstet Gynaecol 2007; 27: 123-129.

20 Abbott DH, Dumesic DA, Franks S. Developmental origin of polycystic ovary syndrome - a hypothesis. J Endocrinol 2002; 174: 1-5.

21 Balen A, Conway O, Homberg R, Legro RS. Long-term sequelae of polycystic ovary syndrome. Polycystic Ovary Syndrome: A Guide to Clinical Management. London, UK: Taylor \& Francis, 2005; 93-128.

22 Balen $\mathrm{AH}$, Anderson RA, Policy \& Practice Committee of the BFS. Impact of obesity on female reproductive health: British Fertility Society, Policy and Practice Guidelines. Hum Fertil 2007; 10: 195-206.

23 Zachariah M, Fleming R, Acharya U. Management of obese women in assisted conception units: a UK survey. Hum Fertil 2006; 9: 101-105.
24 Taylor A. ABC of subfertility: extent of the problem. BMJ 2003; 327: 434-436.

25 Rowell P, Braude P. Assisted conception. I - General principles. BMJ 2003; 327: 799-801.

26 van der Steeg JW, Steures $P$, Eijkemans MJ, Habbema JD, Hompes PG, Burggraaff JM, et al. Obesity affects spontaneous pregnancy chances in subfertile, ovulatory women. Hum Reprod 2008; 23: 324-328.

27 Wang JX, Davies M, Norman RJ. Body mass and probability of pregnancy during assisted reproduction treatment: retrospective study. BMJ 2000; 321: 1320-1321.

28 Crosignani PG, Ragni G, Parazzini F, Wyssling H, Lombroso G, Perotti $\mathrm{L}$, et al. Anthropometric indicators and response to gonadotrophin for ovulation induction. Hum Reprod 1994; 9: 420-423.

29 Wass P, Waldenstrom U, Rossner S, Hellberg D. An android body fat distribution in females impairs the pregnancy rate of invitro fertilization-embryo transfer. Hum Reprod 1997; 12: 2057-2060

30 Bellver J, Melo MA, Bosch E, Serra V, Remohi J, Pellicer A, et al. Obesity and poor reproductive outcome: the potential role of the endometrium. Fertil Steril 2007; 88: 446-451.

31 Zaadstra BM, Seidell JC, Van Noord PA, te Velde ER, Habbema JD, Vrieswijk B, et al. Fat and female fecundity: prospective study of effect of body fat distribution on conception rates. BMJ 1993; 3006: 484-487.

32 White DM, Polson DW, Kiddy D, Sagle P, Watson H, GillingSmith C, et al. Induction of ovulation with low-dose gonadotropins in polycystic ovary syndrome: an analysis of 109 pregnancies in 225 women. J Clin Endocrinol Metab 1996; 81: 3821-3824

33 Kiddy DS, Hamilton-Fairley D, Bush A, Short F, Anyaoku V, Reed MJ, et al. Improvement in endocrine and ovarian function during dietary treatment of obese women with polycystic ovary syndrome. Clin Endocrinol 1992; 36: 105-111.

34 Clark AM, Ledger W, Galletly C, Tomlinson L, Blaney F, Wang $X$, et al. Weight loss results in significant improvement in pregnancy and ovulation rates in anovulatory obese women. Hum Reprod 1995; 10: 2705-2712.

35 Moran LJ, Brinkworth G, Noakes M, Norman RJ. Effects of lifestyle modification in polycystic ovarian syndrome Reprod Biomed Online 2006; 12: 569-578.

36 Confidential Enquiry into Maternal and Child Health (CEMACH). Why Mothers Die 2000-2002. London, UK: CEMACH, 2005

37 Bellver J, Busso C, Pellicer A, Remohi J, Simon C. Obesity and assisted reproductive technology outcomes. Reprod Biomed Online 2006; 12: 562-568.

38 Hamilton-Fairley D, Kiddy D, Watson H, Paterson C, Franks S, Hamilton-Fairley $\mathrm{D}$, et al. Association of moderate obesity with a poor pregnancy outcome in women with polycystic ovary syndrome treated with low dose gonadotrophin. $\mathrm{Br} J$ Obstet Gynaecol 1992; 99: 128-131.

39 Sebire NJ, Jolly M, Harris JP, Wadsworth J, Joffe M, Beard RW, et al. Maternal obesity and pregnancy outcome: a study of 287,213 pregnancies in London. Int J Obes Relat Metab Disord 2001; 25: 1175-1182.

40 Linne Y. Effects of obesity on women's reproduction and complications during pregnancy. Obes Rev 2004; 5: 137-143.

41 Galtier-Dereure F, Montpeyroux F, Boulot P, Bringer J, Jaffiol C. Weight excess before pregnancy: complications and cost. Int $J$ Obes Relat Metab Disord 1995; 19: 443-448.

42 McClure N, McQuinn B, McDonald J, Kovacs GT, Healy DL, Burger HG, et al. Body weight, body mass index, and age: predictors of menotropin dose and cycle outcome in polycystic ovarian syndrome? Fertil Steril 1992; 58: 622-624

43 Fridstrom M, Sjoblom P, Pousette A, Hillensjo T. Serum FSH levels in women with polycystic ovary syndrome during ovulation induction using down-regulation and urofollitropin. Eur J Endocrinol 1997; 136: 488-492.

44 Heslehurst $\mathrm{N}$. Trends in maternal obesity incidence rates, demographic predictors, and health inequalities in 36821 women over a 15-year period. Br J Obstet Gynaecol 2007; 114 : 187-194.

45 Clark AM, Thornley B, Tomlinson L, Galletley C, Norman RJ. Weight loss in obese infertile women results in improvement in reproductive outcome for all forms of fertility treatment. Hum Reprod 1998; 13: 1502-1505.

46 Maheshwari A, Scotland G, Bell J, McTavish A, Hamilton M, Bhattacharya $\mathrm{S}$, et al. The direct health services costs of providing assisted reproduction services in overweight or obese women: a retrospective cross-sectional analysis. Hum Reprod 2009; 24: 633-639.

47 Galtier-Dereure F, Boegner C, Bringer J. Obesity and pregnancy: complications and cost. Am J Clin Nutr 2000; 71: 1242S-1248S

48 Counterweight Project Team. Influence of body mass index on prescribing costs and potential cost savings of a weight 
management programme in primary care. $J$ Health Serv Res Policy 2008; 13: 158-166.

49 Pasquali R, Antenucci D, Casimirri F, Venturoli S, Paradisi R, Fabbri R, et al. Clinical and hormonal characteristics of obese amenorrheic hyperandrogenic women before and after weight oss. J Clin Endocrinol Metab 1989: 68: 173-179.

50 Holte J, Bergh T, Berne C, Wide L, Lithell H. Restored insulin sensitivity but persistently increased early insulin secretion after weight loss in obese women with polycystic ovary syndrome. J Clin Endocrinol Metab 1995; 80: 2586-2593.

51 Galletly C, Clark A, Tomlinson L, Blaney F. Improved pregnancy rates for obese, infertile women following a group treatment program. An open pilot study. Gen Hosp Psychiatry 1996; 18: 192-195.

52 Brown I, Thompson J, Tod A, Jones G. Primary care support for tackling obesity: a qualitative study of the perceptions of obese patients. Br J Gen Pract 2006; 56: 666-672.

53 Nelson $\mathrm{P}$, Adamson $\mathrm{A}$, Moore $\mathrm{H}$. Conducting randomised controlled trials in primary care: lessons from an obesity management trial. Br J Gen Pract 2006; 56: 674-679.

54 Lord JM, Norman R. Obesity, polycystic ovary syndrome, infertility treatment: lifestyle modification is paramount. $B M J$ 2006; 332: 609.

55 Balen AH, Rutherford AJ. Managing anovulatory infertility and polycystic ovary syndrome. BMJ 2007; 335: 663-666.

56 Kousta E, White DM, Franks S. Modern use of clomiphene citrate in induction of ovulation. Hum Reprod Update 1997; 3: 359-365.

57 Merhi ZO, Merhi ZO. Weight loss by bariatric surgery and subsequent fertility. Fertil Steril 2007; 87: 430-432.

58 Ramsay JE, Greer I, Sattar N. ABC of obesity. Obesity and reproduction. BMJ 2006; 333: 1159-1162.

59 Wadden TA. Treatment of obesity by moderate and severe caloric restriction. Results of clinical research trials. Ann Intern Med 1993; 119: 688-693.

60 National Health Service. 'Change for Life' website. http://www.nhs.uk/Change4Life [Accessed 8 April 2009].

BOOK REVIEW

Sex and War: How Biology Explains Warfare and Terrorism and Offers a Path to a Safer World. Malcolm Potts, Thomas Hayden. Dallas, TX, USA: Ben Bella Books Inc., 2008. ISBN-13: 978-1-93377-157-1. Price: £18.99. Pages: 457 (hardback)

War is a great horror. All right-thinking people agree on this. War has brought more misery to humanity than any other single thing. Why, then, do we as a species indulge in it so often and so easily? This question has never been as urgent as it is today. The world has never been more fractious and humankind's ability to destroy itself has never been greater. One might think that the need to understand why we kill on an organised and industrial scale should be among our most urgent preoccupations. It need hardly be said, though, that this is not so. Malcolm Potts and Thomas Hayden are not afraid of the question. In their book they plumb the biological origins of what they call the "team aggression" impulse and describe how evolution has favoured it participants. They show how the impulse is an ineradicable part of the creation of society and civilisations. Now, however, we have outgrown it, but the urge is still with us, embedded in our nature

We might think, in the so-called "advanced" societies, that the drive to war is a low impulse that impels others, not us. But recent experience gives the lie. The reasons that were given by the UK and the USA for their wars that still rage in the Middle East were forced and artificial, and were rapidly dropped and changed when they wore thin. An open-minded person could only conclude that the UK and the USA wanted to go to war. In answering why this dark desire exists Potts and Hayden offer a way of defusing it. Their thesis is an intriguing one - enhance the role of women; give them a greater part in society, more control over their own lives, and the rate at which they reproduce. This amounts to an effective curb of the dark impulse - and here lies the rationale for readers of this journal having not only an interest but also potentially a vital role to play, in the prevention of war. Nothing less.

Reviewed by Lester Venter Freelance Writer, London, UK

\section{Sexual health specialists}

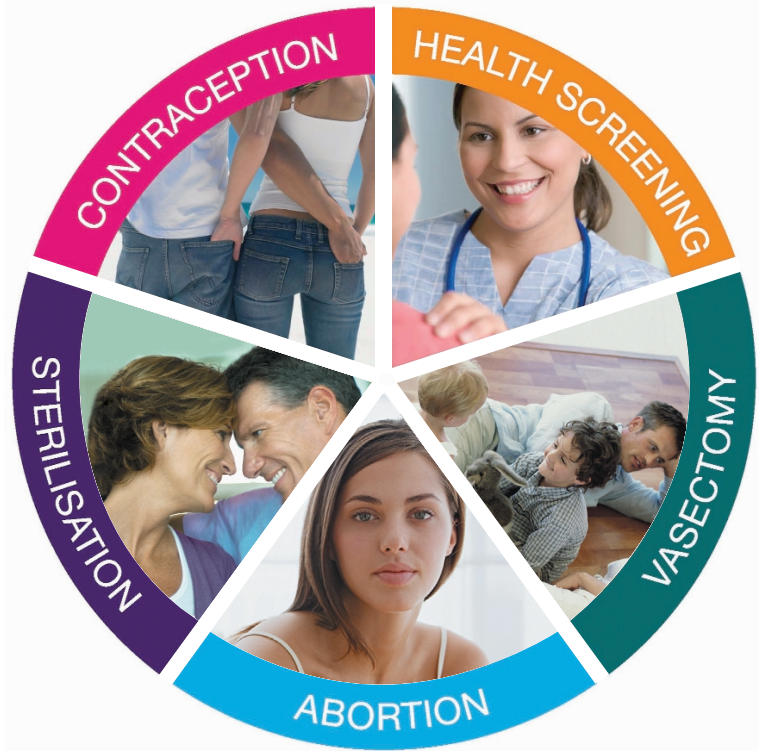

Marie Stopes International centres around the UK provide expert care and support for clients 24 hours. We are chosen by over 70 Primary Care Trusts to support their local sexual health services.

For more information or a sexual health pack call 08451203644 www.mariestopes.org.uk we advise...you decide.

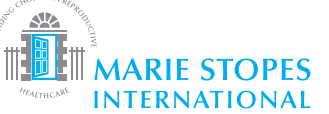

\section{Lubrication ...naturally}

SYLK natural personal lubricant for the alleviation of atrophic vaginitis is now included within the NHS Drug Tariff Part IX and available on an FP10.

Adopted and endorsed by a multiprofessional group investigating the use of vaginal dilators following pelvic radiotherapy, as well as members of the National Committee of the National Forum of Gynaecology Oncology Nurses (NFGON) and other relevant groups within the NHS, SYLK

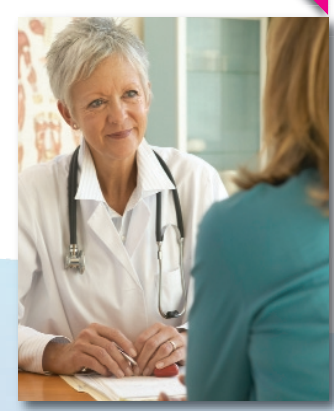

- has a non chemical base derived from an extract of the kiwi fruit plant that effectively mimics a woman's natural secretions and is the only paraben free lubricant

- has passed cytotoxicity, sensitisation and product stability tests. The $\mathrm{pH}$ of SYLK is controlled within 4.5 to 4.7, to equate with the vaginal environment

- is a class 1 medical device available in one $40 \mathrm{ml}$ size, sufficient for up to 150 applications

Free samples and consumer literature are readily available from:

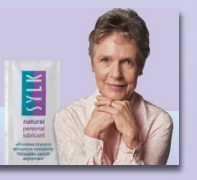

SYLK Limited

FREEPOST, PO Box 340 Rickmansworth, WD3 5WD Tel: 08709506004 www.sylk.co.uk 